\title{
Preoperative psychological evaluation of transplant patients: challenges and solutions
}

\author{
This article was published in the following Dove Press journal: \\ Transplant Research and Risk Management \\ 26 June 2015 \\ Number of times this article has been viewed
}

\author{
Martin Kumnig' \\ Sheila Jowsey-Gregoire ${ }^{2}$ \\ 'Center for Advanced Psychology \\ in Plastic and Transplant Surgery \\ (CAPPTS), Department of Medical \\ Psychology, Medical University \\ of Innsbruck, Innsbruck, Austria; \\ ${ }^{2}$ Department of Psychiatry and \\ Psychology, Mayo Clinic, Rochester, \\ MN, USA
}

\begin{abstract}
Psychological assessments are crucial for the evaluation and optimization of the suitability of transplant patients. The interdisciplinary evaluation in modern transplantation medicine focuses on important psychosocial issues, such as assessing patients' characteristics that predict best postoperative outcome after solid organ transplantation. When assessing patients for reconstructive hand transplantation, the psychological evaluation should identify whether reconstructive hand transplantation is the best treatment option to regain functionality and sensation, to resolve body image concerns, and to improve health-related quality of life (HRQOL) for each patient. These psychosocial issues in transplantation medicine are receiving increased attention; however, standardized psychological evaluation and follow-up protocols are still being developed. Previously published reports in transplantation medicine have attempted to identify psychosocial factors important in the evaluation of transplant patients and that predict psychosocial outcomes. This review will provide an overview of recent investigations in solid organ and vascularized composite allotransplantation (VCA), including the domains of evaluation, pre- and posttransplant follow-up, psychiatric complications, evaluation of body image, and HRQOL. Recent work highlights the potential for a multicenter research approach utilizing standardized assessment strategies and emphasizing the need for a shared assessment approach to understand psychosocial outcomes. For example, the Chauvet Workgroup convened in 2014 in Paris with stakeholders in the assessment of psychosocial factors to discuss key areas and propose an ongoing shared effort across centers in addressing important questions related to psychosocial care of VCA. A successful transplantation requires a multistaged multidisciplinary psychosocial evaluation to identify those most suited to solid organ or reconstructive transplantation and minimize psychological morbidity. With this in place, current transplant psychosocial practices can be useful for solid organ transplantation and refined for VCA. This review will present potential challenges and solutions for guideline development in both solid organ and VCA.
\end{abstract}

Keywords: assessment, evaluation, multicenter research approach, psychology, psychometric instruments, standardization, transplantation

\section{Introduction}

In modern transplantation medicine the preoperative psychological evaluation of transplant patients is equally important as the medical assessment in determining patients' eligibility for solid organ or reconstructive transplantation. ${ }^{1,2}$ It is widely accepted that several psychosocial and medical risk factors place transplant patients at higher risk for non-adherence and negative medical and/or psychological postoperative outcomes such as the development of depressive symptoms, posttraumatic stress reactions, or regression. ${ }^{3}$ The pre- and postoperative psychological evaluation of patients for solid 
organ or reconstructive transplantation should be integral parts of any transplant program.

Nevertheless, there are fields in transplantation medicine where the standardized psychological evaluation still represents a relatively new approach such as the preoperative assessment of patients for vascularized composite allotransplantation (VCA). Patients suffering from the loss of a hand or an upper extremity have to cope with multiple challenges. ${ }^{4}$ Thus, the identification of at-risk patients and those requiring ongoing counseling are a primary focus of the psychological evaluation. ${ }^{5}$

Goals of the psychological evaluation include selection of patients most likely to benefit from transplantation and identification of areas for psychological intervention, both before and after transplantation. ${ }^{6,7}$ The preoperative psychological evaluation should address the patients' premorbid psychiatric state, past adaption to stressors and coping skills, history of adherence to treatment and medication self-management, substance abuse history, potential posttraumatic reactions because of organ loss, anxiety and depression, health-related quality of life (HRQOL) and general health behaviors, quality of affect, mental status, level of daily activities and social support, including community and faith-based support systems. ${ }^{4,5,8-13}$ It may also be useful to administer standardized evaluation protocols including psychometric screening tools to evaluate psychosocial factors relevant to transplantation. ${ }^{6}$

Careful preoperative psychological evaluation is essential to review patients for psychosocial factors that are predictive of symptom emergence and nonadherence, while close follow-up posttransplantation can help improve outcomes. Additionally, specific interventions that take into account the unique psychological and medical needs of transplant patients need to be further developed. ${ }^{14}$ Improved strategies for identifying high-risk patients and finding ways to intervene both pre- and posttransplantation may not only help lengthen transplant recipients' life spans, but also improve their adaptation to transplantation and lead to improved HRQOL. ${ }^{6,15}$

A comprehensive systematic review of the literature was conducted by reviewing manuscripts, which describe psychiatric or psychological assessment of patients before and after solid organ transplantation or VCA. We screened citations from MEDLINE, EMBASE, Web of Science, Psych INFO, Sociological Abstracts, and CINAHL databases. Terms such as transplantation, solid organ transplantation, allotransplantation, allograft, assessment, evaluation, hand transplantation, psychiatric, psychological, and psychosocial were used in the search strategies. The "Related Articles" feature on PubMed and reference lists of all included studies were also reviewed. We attempted to identify manuscripts that addressed the psychiatric or psychological impact of solid organ transplantation or VCA. The eligibility of each citation was evaluated and the manuscripts were retrieved for any citation considered potentially relevant.

Given the influence of psychological factors on the success of solid organ transplantation or VCA, research on psychological factors will be an ongoing focus in the field. This review will provide an overview of recent clinical practices, research, and consensus opinion in solid organ and VCA, regarding the domains of evaluation, pre- and posttransplant follow-up, psychiatric complications, evaluation of body image, and HRQOL. In addition, information to guide selection of patients will be given and the importance of a multicenter research approach will be addressed. As recent work has provided a more complete picture of the complexities of the psychosocial factors in transplantation medicine, standardized evaluation and follow-up protocols could capitalize on the collective diverse clinical experiences from centers. As a result, psychological risk factors for both poor psychosocial and medical/surgical outcomes could be identified resulting in identification of patients in need of supportive treatment in the course of transplantation.

\section{Psychological aspects in transplantation medicine}

A multidisciplinary team of dedicated transplant professionals should assess the patients' ability to successfully navigate the complexities of pre- and posttransplant life. In this context, a key member of the transplant team is the transplant psychiatrist or psychologist, who is responsible for the patients' psychological evaluation (eg, pre-transplant risk assessment and eligibility for transplantation) as well as for ongoing counseling and posttransplant follow-up. . $^{14,16,17}$

Evaluation of expectations in transplantation medicine includes an assessment of the expectations of the patients, their families, and the transplant team. With respect to patients' expectations, two questions arise: 1) What do the patients hope to gain from the surgery? Patients' goals may include improved health and physical function, decreased pain, and their improved HRQOL; 2) Are the patients' expectations realistic? This encompasses whether the patient understands the potential surgical complications, the risks of immunosuppression, the potential for rejection and graft loss, ${ }^{18}$ and the need for adherence to the therapeutic regimen. ${ }^{19}$ Particularly, the transplant team expects that the patient will adhere to medical recommendations, including medical appointments, laboratory draws, and medications. The team 
expects that the patient will maintain good communication, alerting the team regarding any changes in health status. Therefore, establishing a therapeutic alliance is a key to foster good communication. One way to align the expectations of team and patient is through education of the patients and their families. In addition to communication strategies that are essential components of psychological evaluation, the clinical interview of the patients themselves and their families helps to create a meaningful understanding of the patients' unique circumstances and past psychiatric history while psychometric instruments may help to reveal the patients' psychological coping strategies and symptom burden. ${ }^{20}$

Practitioners may employ a variety of psychometric instruments to complement their clinical evaluation. Centers vary widely in terms of the types of instruments used and the weight that the instruments carry in their clinical decision-making. There is currently no international consensus on which instruments may contribute to optimal candidate selection.

Optimization of patient selection is also important because of the patients' risk to develop a psychiatric disorder before transplantation as well as during the posttransplant period. ${ }^{21,22}$ Fortunately, the large majority of transplanted patients are usually satisfied with the outcome of transplantation and their improved general health and HRQOL. ${ }^{23-26}$ However, a small number of patients posttransplant report the following disorders: major depression or recurrence of depression, ${ }^{27-32}$ family dysfunction, ${ }^{20,23,33}$ anxiety disorders, ${ }^{34,35}$ and drug and/or alcohol abuse. ${ }^{36-40}$ Therefore, the underlying conditions should be treated and will require close monitoring for emerging psychological symptoms before and after transplantation.

\section{Domains of psychological evaluation and follow-up}

Robust preoperative psychological evaluation protocols will aid transplant teams in providing relevant information for the interdisciplinary decision-making process on patients' eligibility for transplantation. This will then enable the selection of patients most likely to benefit from transplantation. In addition, highly selective evaluation protocols will identify areas for supportive psychological intervention, both before and after transplantation. The psychological evaluation and follow-up protocols ideally will address the following psychosocial domains.

\section{Premorbid psychiatric state}

A careful history of the patients' past psychiatric conditions and treatments including psychotherapies, medication trials including names of medications, dosages, and duration of use are helpful. Collateral history from family members and local providers can reveal additional information that can help the transplant team to identify higher risk candidates or candidates who would benefit from closer monitoring or additional services.

The assessment of the premorbid psychiatric state is one of the most important domains of psychological evaluation, and diverse psychiatric complications in solid organ and reconstructive transplantation have been described. ${ }^{21,22}$ Pre-existing psychiatric difficulties (eg, mood changes, anxiety and depression, and personality disorders), the initial trauma of diagnosis of a terminal disease or the trauma of amputation (in case of patients considering reconstructive hand transplantation), and adjusting to the transplantation process (eg, adherence to medication) appear to be important factors. Somatic symptoms may be a sequelae of maladaptive psychological functioning. In particular, during the time period of surgery, rejection episodes and delayed function, difficulty with the rehabilitation, and side effects of immunosuppressive treatment may cause mood changes, anxiety, as well as depressive reactions that require supportive treatment.

Patients with personality disorders require close psychiatric pre-transplant evaluation and posttransplant follow-up, because they may experience an exacerbation or reactivation of maladaptive coping and psychiatric symptoms in the setting of transplantation. ${ }^{41,42}$

A potential increased risk of non-adherence to treatment has been observed in patients with a prolonged hospitalization, psychological regression, addiction, relational difficulties, and/or diverse behavioral problems. ${ }^{43}$ Also, psychotic reactions may put the patients at higher risk for non-adherence, especially in the setting of high dose opiates, steroid treatment, and/or the patients' inability to accept and successfully integrate the graft. Notably, the stress of the surgical procedure can lead to relapse to addictions so that the patients' ability to manage complex posttransplant medical regimens is at risk. On rare occasions following transplantation, patients are ambivalent about transplantation, which may diminish their motivation to manage the medical regimen leading to rejection and graft failure. . $^{3,44}$

\section{Past adaption to stressors and coping skills}

Assessing the patients' past adaptation to medical care is important. The ability to comply with complex medical regimens may predict future compliance with posttransplant medical regimens. ${ }^{3}$ The patients' ability to sustain long-term 
employment and stable relationships provides the transplant team with helpful insights about the patients' ability to form a relationship with the transplant team and to solve problem through complications. Evidence of conflicted past interpersonal relationships may indicate a need for psychological assessment of maladaptive personality traits. ${ }^{41}$ Often, collateral history from previous health-care providers will indicate if there are areas of concern.

\section{Adherence and self-management}

The involvement of the transplant team pharmacist to assess the patients' previous compliance with medications is helpful. ${ }^{45-50}$ Determining whether the patient has a reasonable understanding of their current medications, has been taking medications as prescribed, and checking with the pharmacy to see whether medications have been refilled in a timely manner can be especially helpful. , $^{3,45}$

Recently, attempts have been made to develop specific instruments for the assessment of adherence and self-management. Nevertheless, these efforts are in their infancy and no specific instrument is universally accepted. An example of this would be the Innsbruck Psychological Screening Program for Reconstructive Transplantation use of the Medication Experience Scale by Goetzmann ${ }^{51}$ to evaluate the adherence focusing on immunosuppression after VCA.

\section{Substance abuse}

Reviewing the patients' use of alcohol and exposure to illicit substances are an essential part of the evaluation process. ${ }^{36-40}$ Careful review of consumption patterns, evidence of binge drinking, tolerance, adverse consequences of use, loss of control, and previous chemical dependence treatment is required. For patients with evidence of an abusive pattern of alcohol or substance use, chemical dependence treatment with ongoing participation in a sobriety program such as Alcoholics Anonymous provides the most comprehensive approach to support posttransplant sobriety.

\section{Anxiety, depression, and posttraumatic reactions}

Anxiety $^{34,35}$ and depression ${ }^{27-32}$ are typically detrimental to the outcome of transplantation resulting in poor sleep, compromised nutrition, and decreased motivation for rehabilitation and medical care. Encouraging patients to self-monitor for these symptoms and educating the treatment team about early referral for psychiatric assessment are recommended. Typically, patients can tolerate most serotonin reuptake inhibitors and will be better able to fully participate in posttransplant rehabilitation if their mood symptoms are well treated. The authors refer the reader to standard Psychosomatic Medicine textbooks for further information on prescribing for this population.

\section{General health behaviors and HRQOL}

There is a paucity of literature on general health and HRQOL in transplant patients, ${ }^{52-58}$ although the SF-36 Health Survey ${ }^{59}$ has been used in assessing posttransplant QOL.

There is a widely accepted consensus that general health behavior and HRQOL are important domains of psychological evaluation, and existing protocols and instruments primarily focus on physical and functional outcomes. We know that a one-to-one correlation between physical/functional outcome and the anticipated patients' HRQOL after transplantation does not exist, and that there is a need for measures that capture the subjective experience of transplant patients (patient-centered and incorporating other domains of QOL). ${ }^{60}$ In addition, the ideal instrument would be one that can be used both pre- and posttransplant, to allow longitudinal assessment, and should be culturally sensitive and applicable across multiple sociocultural contexts.

\section{Body image}

Body image issues are important psychosocial factors to address during the pre- and posttransplant evaluation of transplant patients, both in solid organ and particularly in reconstructive transplantation. Ideally, the psychological evaluation provides relevant information regarding the patients' 'self/body-concept and helps determine whether successful integration of the graft can be expected. ${ }^{61}$

In VCA, the disturbed body image due to the loss of hand(s) is a major factor in psychological and social wellbeing and may precipitate a range of concealing behaviors in response to negative self-evaluation and possibly a body image disorder. ${ }^{62-65}$ Body image issues are especially important for patients considering VCA, because the allograft is visible $8,66,67$ and is intimately connected to the patients' self-/ body concept. ${ }^{4,5}$ These significant body image issues should be identified and addressed by standardized pre- and posttransplant evaluation procedures to facilitate processing changes in body image that occur during the transplant process. ${ }^{4,58} \mathrm{An}$ inability to psychologically integrate the transplanted hand may result in non-adherence to medications, which in turn will lead to rejection and may necessitate amputation. ${ }^{69}$

Additionally, incorporating the body image issues of patients' relatives (eg, "Will I be able to accept that my husband will touch me with his new hands?") can be critical to the patients' ultimate acceptance of visible allografts. 
Finally, pro-active strategies and psychosocial interventions to support the patients in their self-concept or body image processing should be considered if disordered body image is identified pre-transplant.

\section{Quality of affect and mental status}

In addition to the evaluation of the premorbid psychiatric state, the assessment of the mood and mental status of transplant patients is needed to determine their eligibility for transplantation. Pre-transplant screening procedures and posttransplant follow-up ratings should evaluate whether the patients show understandable anxiety, fear, and sadness or whether these symptoms suggest psychiatric pathology. Also, the assessment of patients' cognitive abilities is important and should be incorporated into pre- and posttransplant protocols, ${ }^{16}$ to ensure that the patients understand the surgical procedure, all transplant-associated risks, and comply with posttransplant immunosuppressive regimens.

While the desire of chronically ill patients to be restored to full physical function is understandable, they may be unrealistic about how much psychological and physical restoration they will experience resulting in minimization of the risks of the surgery and postoperative transplant regimen. ${ }^{44}$ Thus, desired HRQOL outcomes must be weighed against the surgical procedure that carries medical risks, ${ }^{70}$ especially in case of patients considering VCA. Critics have argued that exposing transplant recipients to the risks of non-specific immunosuppression ${ }^{71,72}$ for the benefit of "nonlife-saving" treatments is unjustified. ${ }^{73}$ Ultimately, risk versus benefit decisions need to be grounded in a personal frame of reference, ${ }^{73-77}$ taking HRQOL factors into account including functional improvement, sense of identity, and risk tolerance decision-making which is different from solid organ transplantation which is largely motivated by survival rates. ${ }^{71}$ Additionally, pre-transplant treatment may be lengthy and circumstances may change over time. During this time, the patient's values may also change, so information, evaluation of that information, and the decisions about transplantation should be an ongoing process. ${ }^{78}$ Thus, it is worth emphasizing the importance of understanding the patients' understanding of the treatment, limitations, and possibilities. ${ }^{79}$ Most studies have come to the conclusion that the choice of treatment modality has to be judged on wider criteria that must include all relevant psychosocial aspects. ${ }^{80}$

\section{Daily activities and social support}

In particular, the daily life of transplant patients is characterized by their medical regimen (eg, adherence to posttransplant immunosuppressive treatment), so social support is essential to assist patients in their daily activities, helping to normalize their life. Beside potential posttransplant side effects and complications, ${ }^{81,82}$ the overall health and particularly the HRQOL $^{23-26}$ of transplant patients generally improve after successful organ transplantation or VCA.

Taking the pre-transplant status of chronically ill patients who need a solid organ transplantation or amputees considering VCA into account, their life is dominated by the medical regimen and their daily activities are restricted. ${ }^{44}$ In the pretransplant phase, eg, waiting for transplantation, the family support and social assistance is especially important. ${ }^{17,83}$

For instance, patients with end-stage renal disease (ESRD) are faced with several restrictions resulting from ESRD $^{79}$ and with varying modes of treatment. ${ }^{78}$ Diverse psychosocial stressors such as loss of self-concept and selfesteem, feeling of uncertainty about the future, and feeling of guilt toward family members ${ }^{23}$ negatively affect the patients' social, financial, and psychological well-being. ${ }^{84-86}$ Although kidney transplantation is generally recognized as the best treatment for ESRD (overview by Tonelli et al), ${ }^{87}$ the demand for kidneys exceeds the supply by far. ${ }^{16}$ For the majority of ESRD patients, alternative modalities for a renal replacement therapy such as hemodialysis and peritoneal dialysis remain the most common treatment options. ${ }^{88}$ The enormous impact of dialysis on HRQOL of ESRD patients has been emphasized. ${ }^{23}$ It is therefore imperative that the choices offered and made are in line with what the patients need and want. ${ }^{89}$ In most cases, the patients' dialysis choice depends more on how the treatment will fit into the patients' life rather than on clinical indicators. ${ }^{78,89-91}$

\section{Multicenter research and standardization}

Multicenter research approaches and standardized protocol development will be important to advance the field of psychological evaluation in transplantation medicine ${ }^{16,92}$ and we will review some of the challenges moving forward with these research endeavors.

Our literature review revealed that there are differences between Europe and the US. For example, there are European research initiatives that describe (but do not standardize) practices for living donors, including the European Living Donor Psychosocial Follow-Up research project ${ }^{93}$ and the European Society for Organ Transplantation initiative in a similar vein (ELPAT).$^{94}$ On review of research initiatives in the US, little has been written on the standardized psychosocial evaluation of transplant recipients or donors. There 
are transplant programs in the US, such as the Mayo Clinic Rochester, that are taking important steps to standardize their protocols across sites using semistructured interviews and shared evaluation protocols rating overall transplant candidacy, mood symptoms, alcohol and substance use, and cognitive screening if applicable. Several hundred programs are reportedly using Stanford Integrated Psychosocial Assessment for Transplantation ${ }^{95}$ to standardize the assessment of transplant candidates. Data on how or whether this standardization impacts reliability of assessment or of transplant outcomes (psychosocial or otherwise) are just beginning to emerge. ${ }^{92}$

While some have emphasized the need for a standardized multicenter research approach, like the Chauvet research group, our understanding is that there is fairly little evidencebased work to promote the standardization of transplant psychological evaluation at this time. We note the work of the Chauvet research group in VCA, however, similar research initiatives that focus on standardization have not been identified in solid organ transplantation. ${ }^{4}$ This collaborative approach is just a starting place for better understanding VCA patients and this initiative hopefully will advance with the participation from multiple centers culminating in VCAspecific instruments that do not currently exist.

In addition, certain characteristics of VCA are uniquely different from solid organ transplantation. One key difference between the psychological assessment in solid organ transplantation and VCA is that in solid organ transplantation little attention is given to body image. Additionally, solid organ transplantation assesses for QOL domains that may not be as relevant in VCA, for example, the psychological assessment of lung transplant patients asks about activities of daily living to evaluate how impaired they are from their lung disease (eg, physical limitations and how much they can do before they become short of breath), rather than how distressed or frustrated they are about not being able to brush their teeth or shave their own face, or eat by themselves. Patients' motivation for VCA can emerge from a variety of concerns related to functional and occupational limitations, body image concerns, and the desire to have the sensation of touch, etc. Therefore, assessing motivation for VCA is a complex and highly important psychological task since patients are not medically ill unlike solid organ patients.

Another critical difference is the visible nature of the allograft. ${ }^{8,66}$ Grafts of a visible organ impact the patients' self-image, ideas regarding the allograft, and the patients' psychological reactions to the allograft. ${ }^{96}$ If the patients do not succeed in psychologically accepting the allograft, the consequences can be serious such as a poorly integrated sense of self and incorporation. ${ }^{97}$

\section{Conclusion}

In summary, a successful transplantation requires a multistaged multidisciplinary psychosocial evaluation to identify candidates suitable for solid organ or VCA and to minimize psychological morbidity. With such procedures in place, current transplant programs can provide transplant candidates with improved posttransplant outcomes leading to better posttransplant quality of life. Guidelines development with contributions from many stakeholders including psychiatrists, psychologist, social workers, nurse coordinators, chemical dependency experts, and transplant teams will yield improved outcomes for this patient population.

\section{Author contributions}

All authors contributed toward data analysis, drafting and revising the paper and agree to be accountable for all aspects of the work.

\section{Disclosure}

The authors report no conflicts of interest in this work.

\section{References}

1. Petit F, Minns AB, Dubernard JM, Hettiaratchy S, Lee WP. Composite tissue allotransplantation and reconstructive surgery: first clinical applications. Ann Plast Surg. 2003;237:19-25.

2. Hettiaratchy S, Randolph MA, Andrew Lee WP. Long-term consideration of hand transplantation. Transplantation. 2003;75:1605.

3. Dobbels F, Vanhaecke J, Dupont L, et al. Pretransplant predictors of posttransplant adherence and clinical outcome: an evidence base for pretransplant psychosocial screening. Transplantation. 2009;87:1497-1504

4. Kumnig M, Jowsey SG, DiMartini A. Psychological aspects of hand transplantation. Curr Opin Organ Transplant. 2014;19:188-195.

5. Kumnig M, Jowsey SG, Rumpold G, et al. The psychological assessment of candidates for reconstructive hand transplantation. Transpl Int. 2012;25:573-585.

6. Jowsey SG, Taylor M, Schneekloth TD, Clark MM. Psychosocial challanges in transplantation. J Psychiatr Pract. 2001;7:404-414.

7. Delmonico FL. A report of the Amsterdam Forum on the care of the live kidney donor: data and medical guidelines. Transplantation. 2005;79: S53-S66.

8. Kumnig M, Jowsey SG, Moreno E, Brandacher G, Azari K, Rumpold G. An overview of psychosocial assessment procedures in reconstructive hand transplantation: the past, present, and future in psychosocial assessment of patients undergoing reconstructive hand transplantation. Transpl Int. Epub November 14, 2013.

9. Clemens KK, Thiessen-Philbrook H, Parikh CR, et al. Psychosocial health of living kidney donors: a systematic review. Am J Transplant. 2006;6:2965-2977.

10. Kalantar-Zadeh K, Kopple JD, Block G, Humphreys MH. Association among SF-36 quality of life measures and nutrition, hospitalization, and mortality in hemodialysis. J Am Soc Nephrol. 2001;12:2797-2806. 
11. Kutner NG, Jassal S. Quality of life and rehabilitation of elderly dialysis patients. Semin Dial. 2002;15:107-112.

12. Kimmel PL, Emont SL, Newmann JM. ESRD patient quality of life: symptoms, spiritual beliefs, psychosocial factors, and ethnicity. Am J Kidney Dis. 2003;42:713-721.

13. Kalantar-Zadeh K, Unruh ML. Health related quality of life in patients with chronic kidney disease. Int Urol Nephrol. 2005;37:367-378.

14. Dew MA, DiMartini AF, DeVito Dabbs AJ, et al. Preventive intervention for living donor psychosocial outcomes: feasability and efficacy in a randomized controlled trial. Am J Transplant. 2013;13 2672-2684.

15. Wintner LM, Giesinger JM, Kemmler G, et al. Verwendung und Nutzen von patient-reported outcomes in der onkologischen Behandlung: eine Übersicht [The benefits of using patient-reported outcomes in cancer treatment: an overview]. Wien Klin Wochenschr. 2012;124 293-303.

16. Dew MA, Jacobs CL, Jowsey SG, Hanto R, Miller C, Delmonico FL. Guidelines for the psychosocial evaluation of living unrelated kidney donors in the United States. Am J Transplant. 2007;7:1047-1054.

17. Dew MA, Switzer GE, DiMartini A, Myaskovsky L, Crowley-Matoka M. Psychosocial aspects of living organ donation. In: Tan HP, Marcos A, Shapiro R, editors. Living Donor Transplantation. New York, NY: Informa Healthcare; 2007:7-26.

18. Goldade K, Sidhwani S, Patel S, et al. Kidney transplant patients' perceptions, beliefs, and barriers related to regular nephrology outpatient visits. Am J Kidney Dis. 2011;57:11-20.

19. Matas AJ, Halbert RJ, Barr ML, et al. Life satisfaction and adverse effects in renal transplant recipients: a longitudinal analysis. Clin Transplant. 2002;16:113-121.

20. Kaller T, Petersen I, Petermann F, Fischer L, Grabhorn E, Schulz KH. Family strain and its relation to psychosocial dysfunction in children and adolescents after liver transplantation. Pediatr Transplant. 2014;18: 851-859.

21. Pither C, Green J, Butler A, et al. Psychiatric disorders in patients undergoing intestinal transplantation. Transplant Proc. 2014;46: 2136-2139.

22. Rosenberger EM, Dew MA, Crone C, DiMartini AF. Psychiatric disorders as risk factors for adverse medical outcomes after solid organ transplantation. Curr Opin Organ Transplant. 2012;17: 188-192.

23. Timmers L, Thong M, Dekker FW, et al. Illness perceptions in dialysis patients and their association with quality of life. Psychol Health. 2008;23(6):679-690.

24. Fiebiger W, Mitterbauer C, Oberbauer R. Health-related quality of life outcomes after kidney transplantation. Health Qual Life Outcomes. 2004;2:2.

25. Neipp M, Karavul B, Jackobs S, Meyer zu Vilsendorf A, Richter N, Becker T. Quality of life in adult transplant recipients more than 15 years after kidney transplantation. Transplantation. 2006;81:1640-1644.

26. Perlman RL, Finkelstein FO, Liu L, et al. Quality of life in chronic kidney disease (CKD): a cross-sectional analysis in the Renal Research Institute-CKD study. Am J Kidney Dis. 2005;45:658-666.

27. Mullish BH, Kabir MS, Thursz MR, Dhar A. Review article: depression and the use of antidepressants in patients with chronic liver disease or liver transplantation. Aliment Pharmacol Ther. 2014;40:880-892.

28. Chilcot J, Spencer BW, Maple H, Mamode N. Depression and kidney transplantation. Transplantation. 2014;97:717-721.

29. Zelle DM, Dorland HF, Rosmalen JG, et al. Impact of depression on long-term outcome after renal transplantation: a prospective cohort study. Transplantation. 2012;94:1033-1040.

30. Tsunoda T, Yamashita R, Kojima Y, Takahara S. Risk factors for depression after kidney transplantation. Transplant Proc. 2010;42: 1679-1681.

31. Favaro A, Gerosa G, Caforio AL, et al. Posttraumatic stress disorder and depression in heart transplantation recipients: the relationship with outcome and adherence to medical treatment. Gen Hospital Psychiatry. 2011;33:1-7.
32. Rogal SS, Landsittel D, Surman O, Chung RT, Rutherford A. Pretransplant depression, antidepressant use, and outcomes of orthotopic liver transplantation. Liver Transplant. 2011;17:251-260.

33. Thys K, Schwering KL, Siebelink M, et al. Psychosocial impact of pediatric living-donor kidney and liver transplantation on recipients, donors, and the family: a systematic review. Transpl Int. 2015;28: $270-280$.

34. Mendes KD, Lopes AR, Martins TA, et al. Relevance of anxiety and stress levels on sleep quality after liver transplantation. Transplant Proc. 2014;46:1822-1826

35. Santos GR, Boin IF, Pereira MI, et al. Anxiety levels observed in candidates for liver transplantation. Transplant Proc. 2010;42:513-516.

36. Rodrigue JR, Hanto DW, Curry MP. Substance abuse treatment and its association with relapse to alcohol use after liver transplantation. Liver Transplant. 2013;19:1387-1395.

37. Pegum N, Connor JP, Young RM, Feeney GF. Psychosocial functioning in patients with alcohol-related liver disease post liver transplantation. Addict Behav. 2015;45C:70-73.

38. Rustad JK, Stern TA, Prabhakar M, Musselman D. Risk factors for alcohol relapse following orthotopic liver transplantation: a systematic review. Psychosomatics. 2015;56:21-35.

39. Dom G, Wojnar M, Crunelle CL, et al. Assessing and treating alcohol relapse risk in liver transplantation candidates. Alcohol Alcohol. 2015;50:162-170.

40. Koljonen V, Fredrik A, Aki R, Heikki M. Self-reported alcohol use and depressive symptoms after liver transplantation. Transplantation. 2015;99(4):867-872.

41. Dobbels F, Put C, Vanhaecke J. Personality disorders: a challenge for transplantation. Prog Transplant. 2000;10:226-232.

42. Weitzner MA, Lehninger F, Sullivan D, Fields KK. Borderline personality disorder and bone marrow transplantation: ethical considerations and review. Psychooncology. 1999;8:46-54.

43. Schaubel DE, Wei G, Dykstra DM, Port FK, Merion RM. Hospitalization patterns before and after liver transplantation. Transplantation. 2007;27: $1590-1594$

44. Sicard D. Ethical aspects of non-life-saving allografts with special regard to the hand. In: Lanzetta M, Dubernard JM, Petruzzo P, editors. Hand Transplantation. Milan: Springer; 2011:107-109.

45. Massey EK, Tielen M, Laging M, et al. Discrepancies between beliefs and behavior: a prospective study into immunosuppressive medication adherence after kidney transplantation. Transplantation. 2015;99: 375-380.

46. Berben L, Denhaerynck K, Dobbels F, et al. Building research initiative group: chronic illness management and adherence in transplantation (BRIGHT) study: study protocol. 2015;71:642-654.

47. Tielen M, van Exel J, Laging M, et al. Attitudes to medication after kidney transplantation and their association with medication adherence and graft survival: a 2-year follow-up study. J Transplant. 2014. Epub 2014 April 28

48. Brar A, Babakhani A, Salifu MO, Jindal RM. Evaluation of nonadherence in patients undergoing dialysis and kidney transplantation: United States transplantation practice patterns survey. Transplant Proc. 2014;46:1340-1346.

49. Nevins TE, Robiner WN, Thomas W. Predictive patterns of early medication adherence in renal transplantation. Transplantation. 2014;98: 878-884.

50. Massey EK, Tielen M, Laging M, et al. The role of goal cognitions, illness perceptions and treatment beliefs in self-reported adherence after kidney transplantation: a cohort study. J of Psychosom Res. 2013;75: 229-234.

51. Goetzmann L, Klaghofer R, Spindler A, Wagner-Huber R, Scheuer E, Buddeberg C. The "Medication Experience Scale for Immunosuppressants" (MESI): Initial results for a new screening instrument in transplant medicine. Psychother Psych Med. 2006;56:49-55.

52. Hjermstad MJ, Kaasa S. Quality of life in adult cancer patients treated with bone marrow transplantation-a review of the literature. Eur $J$ Cancer. 1995;31a(2):163-173. 
53. Jensen SE, Butt Z, Bill A, et al. Quality of life considerations in upper limb transplantation: review and future directions. J Hand Surg Am. 2012;37:2126-2135.

54. Joseph JT, Baines LS, Morris MC, Jindal RM. Quality of life after kidney and pancreas transplantation: a review. Am J Kidney Dis. 2003;42(3):431-445.

55. Kniepeiss D, Wagner D, Pienaar S, et al. Solid organ transplantation: technical progress meets human dignity: a review of the literature considering elderly patients' health related quality of life following transplantation. Ageing Res Rev. 2012;11(1):181-187.

56. Landreneau K, Lee K, Landreneau MD. Quality of life in patients undergoing hemodialysis and renal transplantation - a meta-analytic review. Nephrol Nurs J. 2010;37(1):37-44.

57. Tome S, Wells JT, Said A, Lucey MR. Quality of life after liver transplantation. A systematic review. J Hepatol. 2008;48(4): 567-577.

58. Yang LS, Shan LL, Saxena A, Morris DL. Liver transplantation: a systematic review of long-term quality of life. Liver Int. 2014;34(9): 1298-1313.

59. Ware JE, Snow KK, Kosinski M, Gandek B. SF-36 Health Survey Manual and Interpretation Guide. Boston, MA: New England Medical Center, The Health Institute; 1993.

60. Jay CL, Butt Z, Ladner DP, Skaro AI, Abecassis MM. A review of quality of life instruments used in liver transplantation. $J$ Hepatol. 2009;51:949-959.

61. De Pasquale C, Pistorio ML, Sorbello M, et al. Body image in kidney transplantation. Transplant Proc. 2010;42:1123-1126.

62. Bradbury E. The psychological and social impact of disfigurement to the hand in children and adolescents. Dev Neurorehabil. 2007;10: 143-148.

63. Schwartzer R. Self-efficacy in the adoption and maintenance of health behaviours: theoretical approaches and a new model. In: Schwartzer E, editor. Self-Efficacy: Thought Control of Action. Washington, DC: Hemisphere; 1992:217-242.

64. Rumsey N. Body image and congenital conditions with visible differences. In: Cash TF, Pruzinsky T, editors. Body Image: A Handbook of Theory, Research, and Clinical Practice. New York, NY: Guilford; 2002: 226-233.

65. Rumsey N. Optimizing body image in disfiguring congenital conditions. In: Cash TF, Pruzinsky T, editors. Body Image: A Handbook of Theory, Research, and Clinical Practice. New York, NY: Guilford; 2002: 431-439.

66. Klapheke MM, Marcell C, Taliaferro G, Creamer B. Psychiatric assessment of candidates for hand transplantation. Microsurgery. 2000;20:453-457.

67. Klapheke MM. Transplantation of the human hand: psychiatric considerations. Bull Menninger Clin. 1999;63(2):159-173.

68. Kumnig M, Jowsey SG, Moreno E. Transplant psychiatry: standards in the psychosocial assessment of candidates for reconstructive hand transplantation. Paper presented at: American Society for Reconstructive Transplantation 3rd Biennial Meeting; November 15-17, 2012; The Drake Hotel, Chicago, IL.

69. Petruzzo P, Lanzetta M, Dubernard JM, et al. The international registry on hand and composite tissue transplantation. Transplantation. 2008;86: 487-492.

70. Tobin GR, Breidenbach WC, Klapheke MM, Bentley FR, Pidwell DJ, Simmons PD. Ethical considerations in the early composite tissue allograft experience: a review of the Louisville Ethics Program. Transplant Proc. 2005;37:1392-1395.

71. Simmons PD. Ethical considerations in composite tissue allotransplantation. Microsurgery. 2000;20:458-465.

72. Kalluri HV, Hardinger KL. Current state of renal transplant immunosuppression: present and future. World J Transplant. 2012;24:51-68.

73. Brouha P, Naidu D, Cunningham M, et al. Risk acceptance in compositetissue allotransplantation reconstructive procedures. Microsurgery. 2006;26:144-150.

74. Barker JH, Allen F, Cunningham M, et al. Risk assessment and mangement in hand and facial tissue transplantation. Eur J Trauma. 2011;37: 469-476.
75. Cunningham M, Majzoub R, Brouha PCR, et al. Risk acceptance in composite tissue allotransplantation reconstructive procedures: instrument design and validation. Eur J Trauma. 2004;30:12-16.

76. Lanzetta M, Nolli R, Borgonovo A, et al. Hand transplantation: ethics, immunosuppression and indications. $J$ Hand Surg. 2001;26:511-516.

77. Majzoub RK, Cunningham M, Grossi F, Maldonado C, Banis JC, Barker JH. Investigation of risk acceptance in hand transplantation. J Hand Surg. 2006;31A:295-302.

78. NICE. Peritoneal Dialysis: Peritoneal Dialysis in the Treatment of Stage 5 Chronic Kidney Disease. NICE Clinical Guideline 125. 2011; Available from: http://www.nice.org.uk/guidance/CG125. Accessed February 24, 2014.

79. Grincenkov FR, Fernandes N, Chaoubah A, et al. Factors associated with the quality of life of incident patients on PD in Brazil (BRAZPD). J Bras Nefrol. 2011;33:38-44.

80. Balasubramanian G, McKitty K, Fan SLS. Comparing automated peritoneal dialysis with continuous ambulatory peritoneal dialysis: survival and quality of life differences? Nephrol Dial Transplant. 2011;26:1702-1708.

81. Hautz T, Brandacher G, Zelger B, et al. Immunologic aspects and rejection in solid organ versus reconstructive transplantation. Transplant Proc. 2010;42:3347-3353.

82. Ravindra K, Wu S, McKinney M, Xu H, Ildstad ST. Composite tissue allotransplantation: current challenges. Transplant Proc. 2009;41: 3519-3528.

83. Lukasczik M, Neuderth S, Köhn D, Faller H. Psychologische Aspekte der Lebendnierenspende und -transplantation: Ein Überblick zum aktuellen Forschungsstand. Z Med Psychol. 2008;17:107-123.

84. Ginieri-Coccosso M, Theofilou P, Synodinou C, Tomaras V, Soldatos C. Quality of life, mental health and health beliefs in haemodialysis and peritoneal dialysis patients: investigating differences in early and later years of current treatment. BMC Nephrol. 2008;9:14-22.

85. Christensen A, Ehlers S. Psychological factors in end-stage renal disease: an emerging context for behavioral medicine research. J Consult Clin Psychol. 2002;70:712-724.

86. Griffin KW. Comparison of quality of life in haemodialysis and peritoneal dialysis patients. In: Khanna R, editor. Advances in Peritoneal Dialysis. Toronto, ON: Peritoneal Dialysis Publications; 1994.

87. Tonelli M, Wiebe N, Knoll G, et al. Systematic review: kidney transplantation compared with dialysis in clinically relevant outcomes. Am J Transplant. 2011;11:2093-2109.

88. Álvares J, Cesar CC, Acurcio Fde A, Andrade EI, Cherchiglia ML. Quality of life of patients in renal replacement therapy in Brazil: comparison of treatment modalities. Qual Life Res. 2012;21:983-991.

89. Tong A, Hanson CS, Chapman JR, et al. The preferences and perspectives of nephrologists on patients' access to kidney transplantation: a systematic review. Transplantation. 2014;15:682-691.

90. Kimmel P. Psychosocial factors in dialysis patients. Kidney Int. 2001;59: 1599-1613.

91. Kutner NG, Johansen KL, Kaysen GA, et al. The comprehensive dialysis study (CDS): a USRDS special study. Clin J Am Soc Nephrol. 2009;4:645-650.

92. Rodrigue JR, Pavlakis M, Danovitch GM, Johnson SR, Karp S, Khwaja K. Evaluating living kidney donors: relationship types, psychosocial criteria, and consent processes at US Transplant Program. Am J Transplant. 2007;7:2326-2332.

93. Manyalich M, Menjívar A, Yucetin L, et al. Living donor psychosocial assesment/follow-up practices in the partners' countries of the ELIPSY project. Transpl Proc. 2012;44:2246-2249.

94. Lennerling A, Lovén C, Dor FJ, et al. Living organ donation practices in Europe-results from an online survey. Transpl Int. 2013;26:145-153.

95. Maldonado JR, Dubois HC, David EE, et al. The Stanford Integrated Psychosocial Assessment for Transplantation (SIPAT): a new tool for the psychosocial evaluation of pre-transplant candidates. Psychosomatics. 2012;53(2):123-132.

96. Cherkassky L. A fair trial? Assessment of liver transplant candidates with psychiatric illnesses. Med Ethics. 2011;37:739-742.

97. Carosella ED, Pradeu T. Transplantation and identity: a dangerous split? Lancet. 2006;368:183-184. 


\section{Publish your work in this journal}

Transplant Research and Risk Management is an international, peerreviewed open access journal focusing on all aspects of transplantation and risk management to achieve optimal outcomes in the recipient improving survival and quality of life. The journal welcomes submitted papers covering original research, basic science, clinical studies, reviews \& evaluations, guidelines, expert opinion and commentary, case reports and extended reports. The manuscript management system is completely online and includes a very quick and fair peer-review system, which is all easy to use. Visit http://www.dovepress.com/ testimonials.php to read real quotes from published authors.

Submit your manuscript here: http://www.dovepress.com/transplant-research-and-risk-management-journal 